\title{
Extracting The Video Content by Utilizing Segmentation Kits
}

\author{
S. Ramya, M. Meenaakumari, K. Subbulakshmi
}

\begin{abstract}
The inspiration for removing the substance of data is the openness issue. An issue that is significantly increasingly important for dynamic interactive media information, which likewise must be looked and recovered. Its wealth and unpredictability recommends that there is far to go in removing video highlights, and the usage of increasingly reasonable and successful handling techniques is a significant objective to be accomplished.
\end{abstract}

Key words: color mapping, extraction of content, secular segmentation, Double comparison.

\section{INTRODUCTION}

The extension of the nice assortment and the information available is provoked for getting ready necessities, in spite of recoup matched and profitable information: the transparency issue[1],[3],[5]. The issue is still dynamically huge for differing media message, whereas epic proportions of data must be looked, requested what's increasingly, readied. An extensive segment of the responses for this sort of issues are to expel the pertinent information for the required substance space.

A system which explains about two troublesome errands: selecting what is suitable and evacuating it. Truth is told, while content extraction procedures are sensibly made for information, video information still is generally dull. In spite of its conspicuous tendencies as a correspondence medium, the nonappearance of reasonable arranging and correspondence supports stages has yielded its presentation in a way of added up.

This condition is changing and new video based applications are being made. In our investigation gathering, we are by and by making devices for requesting video documents for later reuse, a system for substance examination of TV news [1], and hyper video structures where hyperlinks are developed subject to substance recognizing evidence in different video streams. These applications hugely rely upon capable computational help, solidifying mind boggling picture examination and taking care of gadgets[2],[4],[6].

Revised Manuscript Received on August 22, 2019.

S.Ramya, Department of Electronics and Communication Engineering, Bharath Institute of Higher Education and Research, Chennai, Tamilnadu, India.E Mail - ramyasamdra@gmail.com

M.Meenaakumari, Department of Electronics and Communication Engineering, Bharath Institute of Higher Education and Research, Chennai, Tamilnadu, India. E Mail -meenumathi.m@gmail.com

K. Subbulakshmi, Department of Electronics and Communication Engineering, Bharath Institute of Higher Education and Research, Chennai, Tamilnadu, India. E Mail -p.sudha50@gmail.com
The made tool stash model offers, in its taking care of fragments, all the handiness of these estimations, covering the use nuances and giving a uniform get to strategies to the unmistakable banner taking care of computations. The focal points offered by the usage of libraries of specific sections have been, as it were, talked about $[1,4]$ : institutionalization, reutilization, flexibility, data reflection and epitome, etc.

\section{VIDEO CEL}

CEL is fundamentally a study of extraction of video content. Its segments extricate important highlights of video information then again used for multiple applications. The item model incorporates segments for video information demonstrating and devices for handling and extricating video content; however as of now the video preparing is confined to pictures. At the information displaying level, the more huge ideas are the accompanying:

- Images, for speaking to the casing information, a numerical grid whose qualities can be hues, shading map sections, and so forth.

- Color Maps, mapping passages into a shading expanse, permitting an extra index.

- Converters will be image and image that handles IO will convert pictures in the particular configurations of the stage what's more, the other way around[7],[9],[11].

Every one of these ideas is spoken to by a $(\mathrm{C}++)$ class and coordinated in a deliberate chain of command. Devices for information handling are connected to the depicted information displaying classes, and furthermore demonstrated as a progression of classes: the ImageOPs, These administrators speak to capacities which are connected to picture districts and concentrate "single-picture" or successive content highlights.

The executed calculations and methodology are portrayed in more detail in the following areas. This model of videoCEL is progressively a complete model subset, which likewise incorporates ideas such has shots, shot groupings and perspectives [1, 11].Ideas, which are displayed in an unmistakable toolbox that gives functionalities to ordering, perusing and playing, clarified video fragments.

Converters will be image and image that handles IO will convert pictures in the particular configurations of the stage what's more, the other way around. The item model incorporates segments for video information demonstrating and devices for handling and extricating video content; however as of now the video 
preparing is confined to pictures.

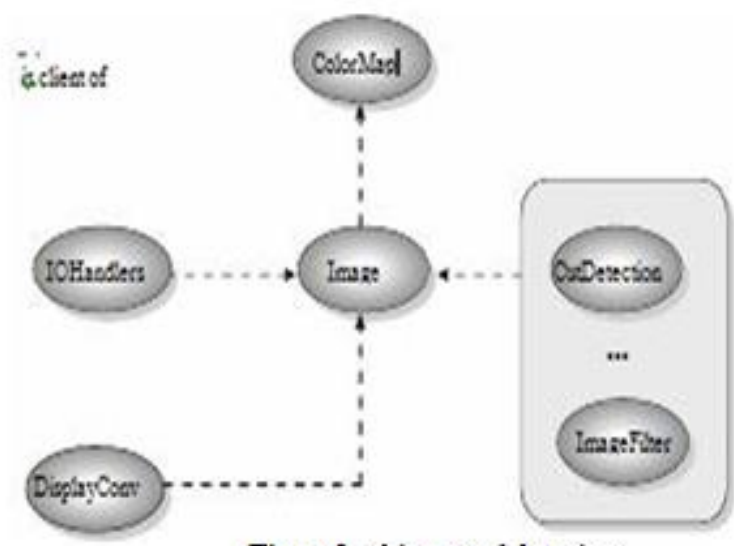

Figurel: object model review

A shot article which is discriminated succession of pictures with a lot of worldly qualities, for example, outlines rate and term and speaks to a video fragment. A shot succession object bunches a few shots utilizing some tactical views. Perspectives are utilized to imagine and peruse frames and frame successions.

\section{SECULAR DIVISION KITS}

A standout amongst the more significant undertakings for investigating the video is to indicate a unit set, where the video fleeting succession might be sorted out [7]. The diverse video advances are significant for video content distinguishing proof [8], to make the discovery one of the essential objectives to be accomplished. The essential supposition of the progress location techniques is that the video fragments are spatially and transiently consistent, and subsequently the limit pictures must endure critical substance changes. The first issue is decreased to the inquiry of appropriate distinction evaluation measurements, whose maximums recognize, with incredible likelihood, the change transient areas.

\section{A. Cut detection}

The way toward distinguishing cuts is very straightforward, essentially on the grounds it is obvious that the adjustments in substance and immediately between sequential envelope. In this way, its prosperity is extraordinarily reliant on the metric reasonableness. The results acquired by applying this technique to a few of our measurements are exhibited straightaway.

The limits choice was made experimentally, while attempting to boost the accomplishment of the discovery (limiting at the same time the false and missed location). The caught video fragment has a place with an outside news report, so its advances are not extremely "creative" (for the most part cuts). Few methodologies are used normally to improve this recognition. [6]. A methodology that was utilized with some accomplishment in past work [11], which attempting to diminish a portion of the absences of the measurements explicit conduct, was just to create a normal of the distinctions acquired with at least two measurements.

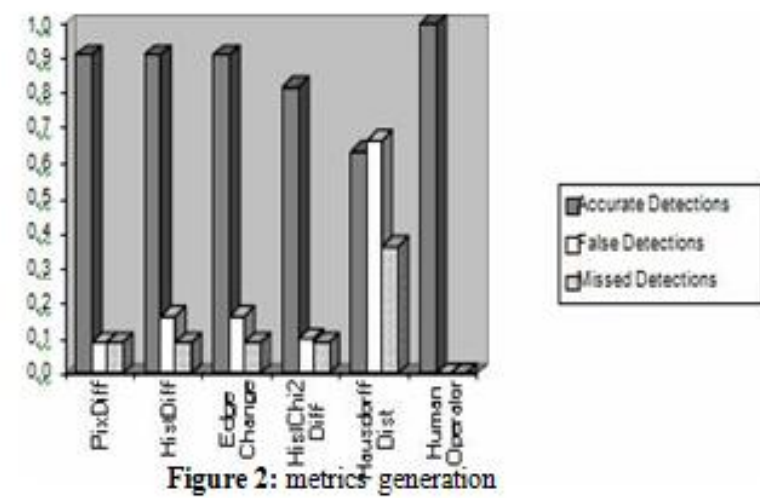

Few methodologies are used normally to improve this recognition. [6]. A methodology that was utilized with some accomplishment in past work [11], which attempting to diminish a portion of the absences of the measurements explicit conduct, was just to create a normal of the distinctions acquired with at least two measurements. Pre-handling pictures utilizing clamor channels or lower goals administrators are likewise very common errands, offering implies for lessening picture the commotion and furthermore the preparing multifaceted nature. The unmistakable treatment of picture locales, so as to dispense with a portion of the more extraordinary qualities, amazingly expands the discovery exactness, particularly when there are just a couple of items proceeding onward the caught scene [7].
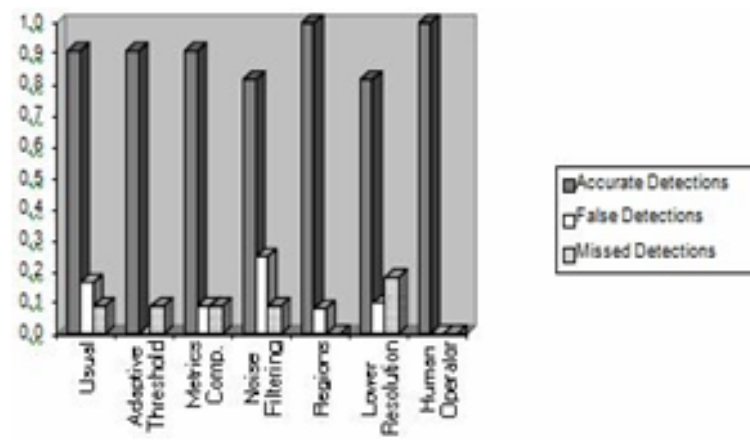

Figure 3: Cut detection

The exactness of the recognition is unmistakably expanded utilizing these procedures, aside from on account of clamor sifting and lower goals. One can really clarify this by safeguarding that the pictures were very perfect so they were obscured with clamor separating system, while the utilizations lower goals pictures is basically a methodology for lessening the calculation unpredictability.

\section{B. Gradual transition detection}

Progressive advances, for example, blurs, disintegrates and wipes, cause increasingly slow changes which advance amid a few pictures. In spite of the fact that the acquired contrasts are less particular from the normal qualities, and can have comparative qualities to the ones brought about by camera activities, there are a few effective strategies, which were adjusted and are presently upheld by the toolbox.

\section{Double-Comparison algorithm}

This calculation [7] was created in the wake of checking that, regardless of the way that the first 
and last progress outlines are very extraordinary, continuous pictures stay fundamentally the same as. Along these lines, as in the cuts location, this method utilizes one of the distinction measurements, it will have double edges: one higher for cuts, and another for the slow changes. While this calculation just identifies progressive changes and recognize them from cuts, there are different methodologies which likewise group blurs, breaks down and wipes, for example, the comparing of edges displayed straightaway.

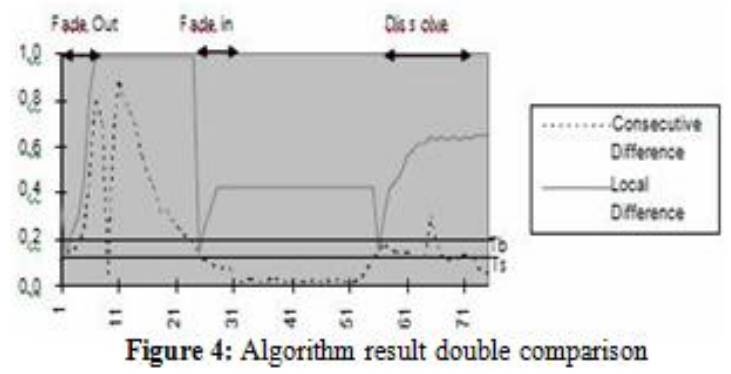

At the point when the successive contrast is among $\mathrm{Tb}$ and $\mathrm{Ts}$, a potential begin is pronounced. At the point when this occurs, the nearby contrast (the distinction between the main casing of the potential fragment and the present edge) begins to be processed. In the event that back to back edges are comparable "enough" while the nearby distinction is high, a continuous change is proclaimed[19],[20].

\section{Algorithm to compare edge}

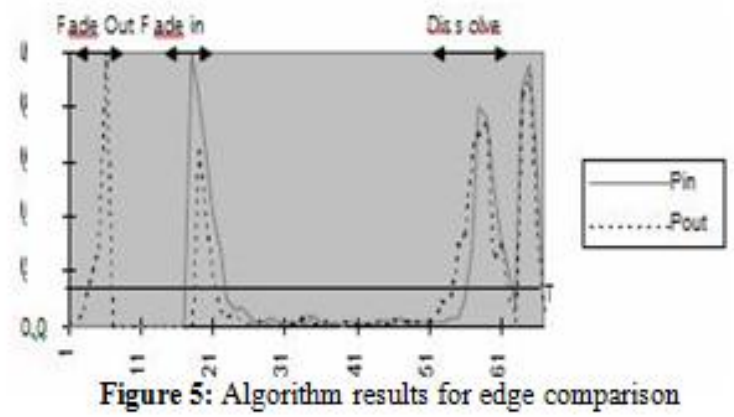

This calculation [6] examinations edge change portions, leaving and entering. Unmistakable steady advances create trademark varieties of these qualities. For example, a blur in dependably creates an expansion in the entering edge part; then again become dim causes an expansion in the leading edge division; a break down has a similar impact as a grow dim pursued by a blur in[14],[16],[18].

\section{DETECTION OF EDGE}

Two particular methodologies for edge location [3] were actualized: (1) inclination module thresholding, where the picture vectors are acquired utilizing the Sobel administrator; (2) the watchful channel, thought about the ideal identifier, which examinations the representatively of angle module maximums, and accordingly creating more slender shapes. As the differential administrators intensify high recurrence zones, usually practice to pre-process the pictures utilizing commotion channels, usefulness likewise upheld by the toolbox as a few smoothing administrators: the middle channel, the normal channel, and a Gaussian channel.

\section{APPLICATIONS}

Mainly this segment it defines about plotting primary attributes of certain implementations worked with the parts and procedures given in videoCEL. The program can stack a stream and split it in its shot portions utilizing cut recognition calculations. Each frame is then spoken to in the program principle window by a symbol. In the program principle window every shot is referred by a symbol. The shots can be played utilizing a few view objects.

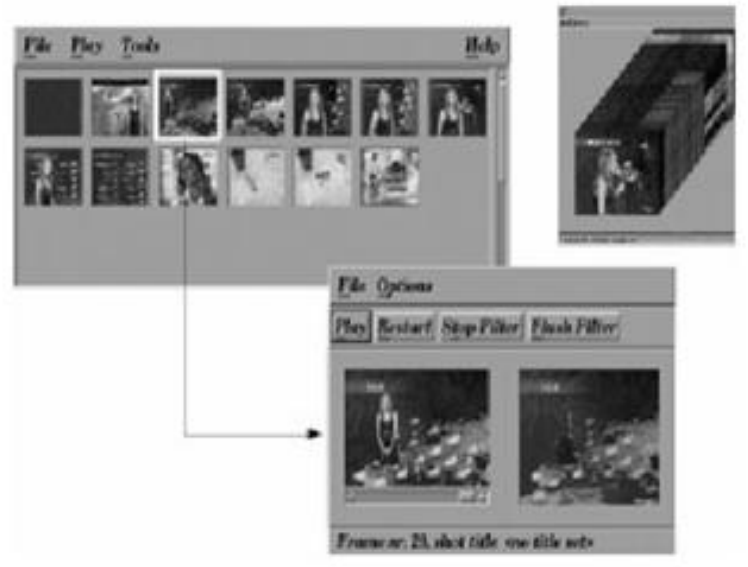

Figure 6: Filtering views

The Weather Digest application [13] produces HTML reports from TV climate estimates. This implementation represents the significance of data sequence.

\section{A. Analysis}

In substance examination of TV news, we enhance a lot of utilizations [1] to be utilized by social researchers. The examination was focused in filling frames including news things span, subjects, and so forth, which our framework endeavors to computerize. To make use of comma and separated values, the HTML pages create a framework which is appropriate. Moreover, for news perusing, these HTML pages can be too utilized, and there additionally device which is based on java for getting to this data.

\section{CONCLUSION}

The toolbox approach is a decent arrangement when one is keen on structure reasonable help for extricating data content, uniquely on the grounds that it very well may be reused and effectively expanded. While there are a few proficient and standardized frameworks for extricating content from pictures, frameworks which are video related still stay very area subordinate. In this unique circumstance, the parts of videoCEL incorporate a huge scope of picture preparing methods that help the retrieving of a few video content highlights.

Many strategies were grown explicitly for video, with announced victories. In any case, we additionally have actualized a few essential, however valuable, picture preparing schedules. These tasks are a piece of the picture content extraction were basically executing to help a portion of the more mind boggling activities, or includes additionally thought to be applicable in sociologies or substance investigation writing. 
As future augmentations, new instruments will before long be added to videoCEL to extricate extra substance highlights. Actually, we are particularly keen on including sound handling. Sound streams contain incredibly important information, likewise extremely rich and various in content. The blend of sound substance extraction apparatuses, with picture systems, will create fascinating outcomes, and in all respects develop the nature of the current investigation.

\section{REFERENCES}

1. Kongkham, D. \& Sundararajan, M. 2019, "Distributed wideband sensing method for faded dynamic spectrum access", International Journal of Innovative Technology and Exploring Engineering, vol. 8, no. 10 , pp. 4309-4312.

2. Balaji, S., John Paul Praveen, A. \& Mohanraj, R. 2019, "Recognizable proof and analysis of palm print in biometric authentication system using bayes techniques", International Journal of Innovative Technology and Exploring Engineering, vol. 8, no. 9 Special Issue 3, pp. 1126-1129.

3. Kavitha, G., Priya, N., Velvizhi, R. \& Allin Geo, A.V. 2019, "Parallel computation in correspondence and signal processing", International Journal of Innovative Technology and Exploring Engineering, vol. 8 , no. 9 Special Issue 3, pp. 1136-1139.

4. Hema, R., Sundararajan, M. \& Balaji, S. 2019, "Smartphone control robot with automatic firing gun", International Journal of Innovative Technology and Exploring Engineering, vol. 8, no. 9 Special Issue 3, pp. 625-627.

5. Kaliyamurthie, K.P., Sundar Raj, B., Velvizhi, R. \& Shanmugapriya, K. 2019, "Dual band paper substrate CPW antenna for wireless applications", International Journal of Innovative Technology and Exploring Engineering, vol. 8, no. 9 Special Issue 3, pp. 605-608.

6. Geo, A.V.A., Arunachalam, A.R., Michael, G. \& Elankavi, R. 2019 "Evaluating architecture using compact modalities", International Journal of Innovative Technology and Exploring Engineering, vol. 8 , no. 9 Special Issue 3, pp. 836-838.

7. Theivasigamani, S., Jeyapriya, D. \& Anita Davamani, K. 2019, "Anamoly analyzing and exploring for wireless sensor networks", International Journal of Innovative Technology and Exploring Engineering, vol. 8, no. 9 Special Issue 3, pp. 1116-1118.

8. Jeyapriya, D., Theivasigamani, S., Velvizhi, R. \& Nandhini, P. 2019, "Program detection in wireless feeler networks", International Journal of Innovative Technology and Exploring Engineering, vol. 8, no. 9 Special Issue 3, pp. 1194-1195.

9. Gowri Sankaran, B., Karthik, B. \& Vijayaragavan, S.P. 2019, "Image compression utilizing wavelet transform", International Journal of Innovative Technology and Exploring Engineering, vol. 8, no. 10, pp. 4305-4308

10. Gowri Sankaran, B., Karthik, B. \& Vijayaragavan, S.P. 2019, "Weight ward change region plummeting change for square based image huffman coding", International Journal of Innovative Technology and Exploring Engineering, vol. 8, no. 10, pp. 4313-4316

11. Hema, R., Sundararajan, M. \& Balaji, S. 2019, "Smartphone control robot with automatic firing gun", International Journal of Innovative Technology and Exploring Engineering, vol. 8, no. 9 Special Issue 3, pp. 625-627.

12. Rangaswamy, K. \& Rajabhushanam, C. 2019, "Congestion control in wireless network using TCP friendly rate control (TFRC)", International Journal of Recent Technology and Engineering, vol. 8, no. 2 Special issue 3, pp. 1598-1602.

13. Tamil Selvan, S. \& Sundararajan, M. 2019, "Performance Parameters of 3 Value 8t Cntfet Based Sram Cell Design Using H-Spice", International Journal of Recent Technology and Engineering, vol. 8, no. 2 Special issue 5, pp. 22-27.

14. Vinoth, V.V. \& Kanniga, E. 2019, "Steganographical techniques in hiding text images - system", International Journal of Recent Technology and Engineering, vol. 8, no. 2, pp. 6535-6537.

15. Saravana, S., Balaji, S., Arulselvi, S. \& John Paul Praveen, A. 2019, "Reliable power quality monitoring and protection system", International Journal of Innovative Technology and Exploring Engineering, vol. 8, no. 9 Special Issue 3, pp. 644-645.

16. Sundaramoorthy, A. \& John Wiselin, M.C. 2019, "Single patch antenna with multiple feed", International Journal of Innovative Technology and Exploring Engineering, vol. 8, no. 9, pp. 1743-1747.
17. Velavan, R., Bharanidharan, S. \& Sheeba, B. 2019, "EMF pollution Causes, effects and protection", International Journal of Innovative Technology and Exploring Engineering, vol. 8, no. 9 Special Issue 3, pp. 1166-1168.

18. Veer, R.A., Arulselvi, S. \& Karthik, B. 2019, "Construction of ensemble square classification approaches in MIMO OFDM", International Journal of Engineering and Advanced Technology, vol. 8, no. 5, pp. 2039-2041.

19. Agitha, W. \& Kaliyamurthie, K.P. 2019, "Improved energy efficient in WBAN using MAC with cloud computing", International Journal of Innovative Technology and Exploring Engineering, vol. 8, no. 8, pp. 2405-2408.

20. Kastro, G.G. \& Wiselin, M.C.J. 2019, "Design and analysis of stub loaded resonator", International Journal of Recent Technology and Engineering, vol. 8, no. 1 Special Issue4, pp. 272-283.

\section{AUTHORS PROFILE}

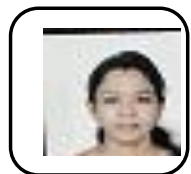

S.Ramya Assistant Professor, Department of Electronics and Communication Engineering, Bharath Institute of Higher Education and Research, Chennai, India.

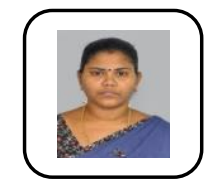

M.Meenaakumari, Assistant Professor, Department of Electronics and Communication Engineering, Bharath Institute of Higher Education and Research, Chennai, India.

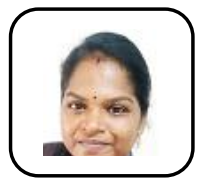

K. Subbulakshmi, Assistant Professor, Department of Electronics and Communication Engineering, Bharath Institute of Higher Education and Research, Chennai, India. 